\title{
Revealing the Cell-Material Interface with Nanometer Resolution by Focused Ion Beam/Scanning Electron Microscopy
}

Citation for published version (APA):

Santoro, F., Zhao, W., Joubert, L. M., Duan, L., Schnitker, J., van de Burgt, Y., Lou, H. Y., Liu, B., Salleo, A., Cui, L., Cui, Y., \& Cui, B. (2017). Revealing the Cell-Material Interface with Nanometer Resolution by Focused Ion Beam/Scanning Electron Microscopy. ACS Nano, 11(8), 8320-8328.

https://doi.org/10.1021/acsnano.7b03494

DOI:

10.1021/acsnano.7b03494

Document status and date:

Published: 22/08/2017

\section{Document Version:}

Typeset version in publisher's lay-out, without final page, issue and volume numbers

\section{Please check the document version of this publication:}

- A submitted manuscript is the version of the article upon submission and before peer-review. There can be important differences between the submitted version and the official published version of record. People interested in the research are advised to contact the author for the final version of the publication, or visit the DOI to the publisher's website.

- The final author version and the galley proof are versions of the publication after peer review.

- The final published version features the final layout of the paper including the volume, issue and page numbers.

Link to publication

\footnotetext{
General rights

- You may freely distribute the URL identifying the publication in the public portal. follow below link for the End User Agreement:

www.tue.nl/taverne

\section{Take down policy}

If you believe that this document breaches copyright please contact us at:

openaccess@tue.nl

providing details and we will investigate your claim.
}

Copyright and moral rights for the publications made accessible in the public portal are retained by the authors and/or other copyright owners and it is a condition of accessing publications that users recognise and abide by the legal requirements associated with these rights.

- Users may download and print one copy of any publication from the public portal for the purpose of private study or research.

- You may not further distribute the material or use it for any profit-making activity or commercial gain

If the publication is distributed under the terms of Article $25 \mathrm{fa}$ of the Dutch Copyright Act, indicated by the "Taverne" license above, please 


\section{agNANO}

\section{Revealing the Cell-Material Interface with Nanometer Resolution by Focused Ion Beam/ Scanning Electron Microscopy}

${ }_{4}$ Francesca Santoro, ${ }^{*}{ }^{\dagger, \text { II }}$ Wenting Zhao, ${ }^{\dagger,}$ Lydia-Marie Joubert, ${ }^{\S}$ Liting Duan, ${ }^{\dagger}$ Jan Schnitker, ${ }^{\|}$ ${ }_{5}$ Yoeri van de Burgt, ${ }_{6}^{\ddagger} \square$ Hsin-Ya Lou, ${ }^{\dagger}$ Bofei Liu, ${ }^{\ddagger}$ Alberto Salleo, ${ }^{\ddagger}$ Lifeng Cui, ${ }^{\perp}$ Yi Cui, ${ }^{\ddagger}, \#$ 6 and Bianxiao Cui* ${ }^{*} \dagger$ (1)

$7{ }^{\dagger}$ Department of Chemistry, ${ }^{\ddagger}$ Department of Material Science and Engineering, and ${ }^{\S}$ CSIF Beckman Center, Stanford University, 8 Stanford, California94305, United States

9 "Institute of Bioelectronics ICS/PGI-8, Forschungszentrum Juelich, Juelich, 52428, Germany

${ }_{10}{ }^{\perp}$ Department of Material Science and Engineering, Dongguan University of Technology, Guangdong 523808, China

${ }_{11}$ \#Stanford Institute for Materials and Energy Sciences, SLAC National Accelerator, Menlo Park, California 94025, United States

12 S Supporting Information
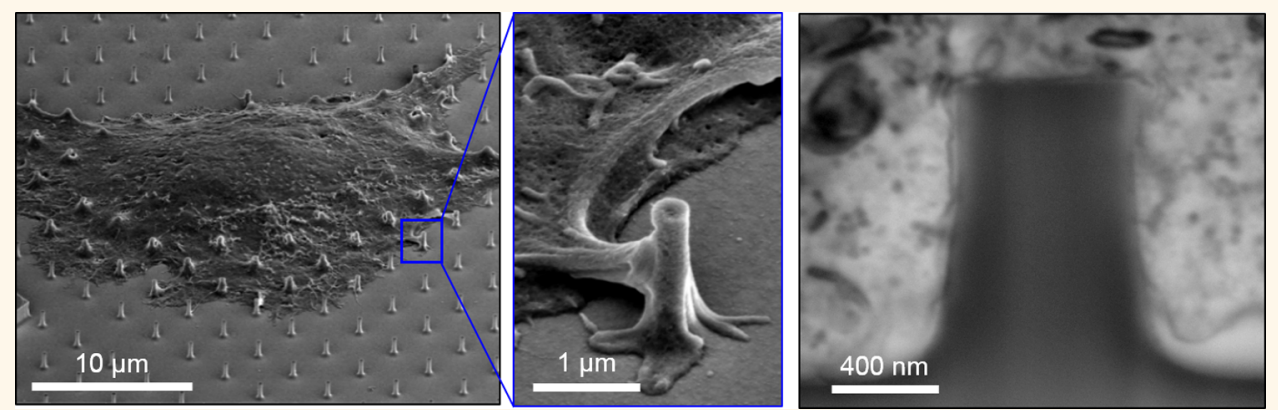

29

30

31 biological materials. ${ }^{1}$ In the case of medical implants, 32 the cell-to-material interface is a key determinant for successful 33 device integration with surrounding tissues, providing mechan34 ical support and minimizing host foreign body responses. ${ }^{2-4}$ 35 Extensive clinical and laboratory studies have shown that surface topologies of nonbiological materials can significantly 36 affect cellular and tissue responses. For example, titanium 37 implants having a rough surface perform much better than 38

Received: May 18, 2017

Accepted: July 6, 2017

Published: July 6, 2017 


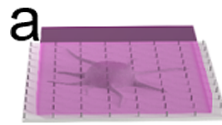

1. Cell Culture

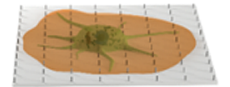

4. Resin Infiltration

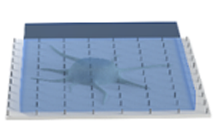

2. Fixation

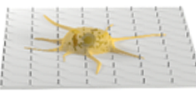

5. Wash

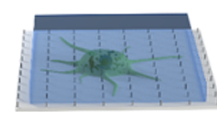

3. Metal Staining

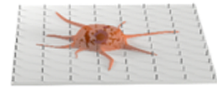

6. Polymerization
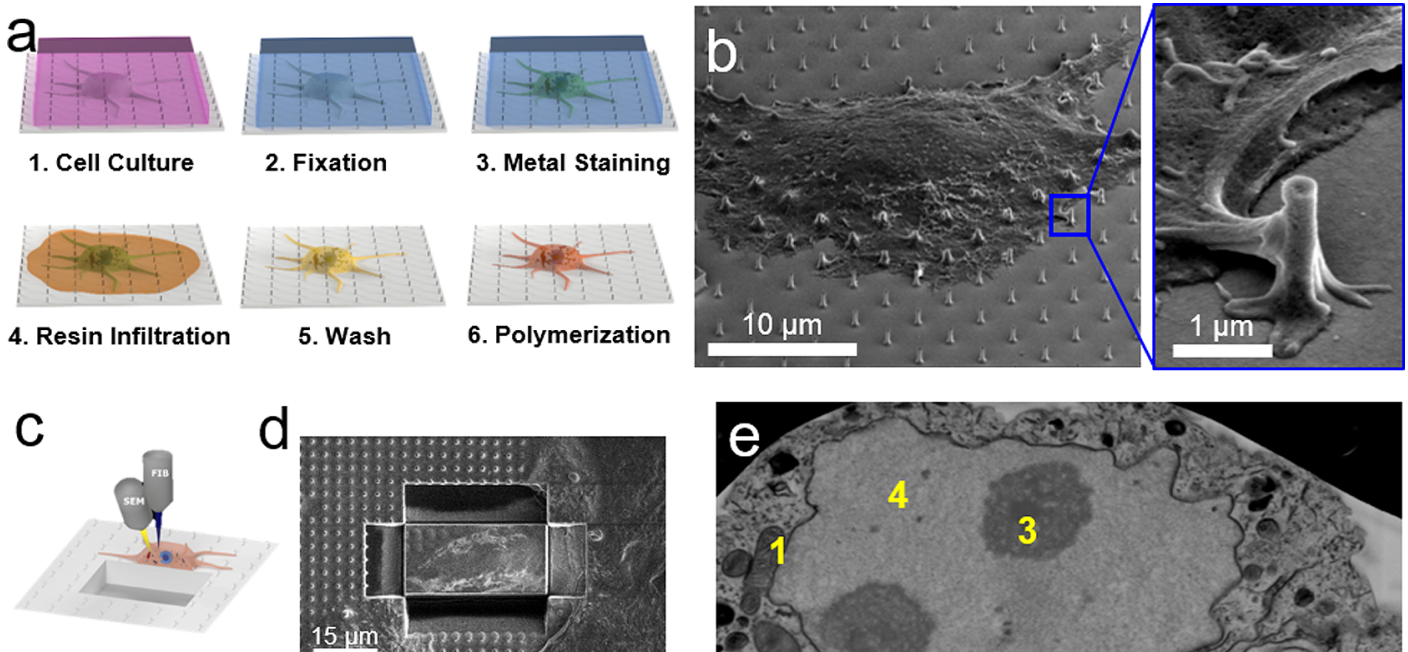

7. Cross Sectioning
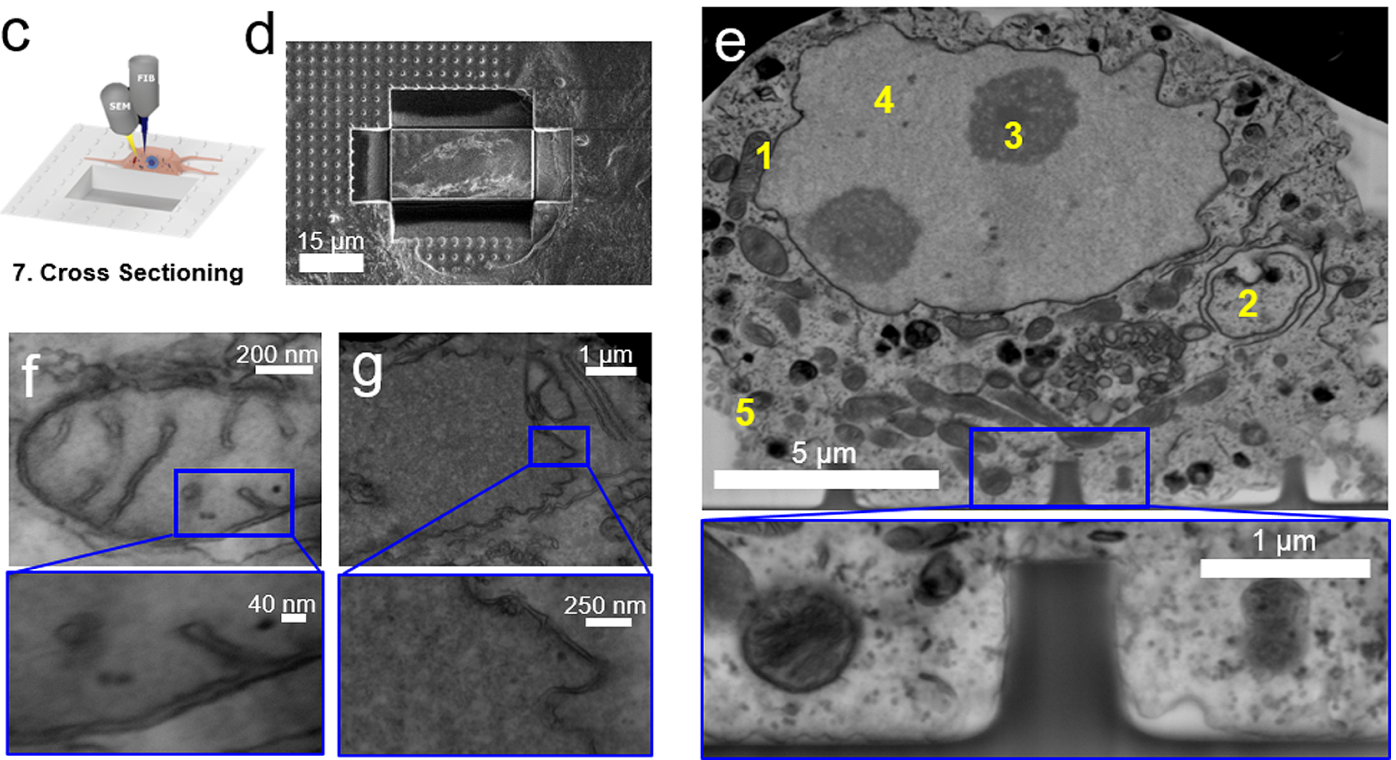

Figure 1. Imaging the cell-to-material interface by FIB/SEM. (a) Schematics of the sample preparation procedure by thin-layer resin plasticization with contrast enhancement. (b) SEM image of a plasticized HL-1 cell on a quartz substrate with nanopillars showing that extracellular resin is removed and the cell morphology is clearly visible. The inset shows that the membrane protrusions in contract with a nanopillar are well preserved. (c) Schematics and (d) experimental results of using FIB milling to cut trenches through the cell and the substrate and open up the interface. (e) SEM image of the interface after FIB milling revealing intracellular compartments and organelles such as mitochondria (1), intracellular membranes (2), nucleoli (3), nucleus (4), and cellular membrane (5). Inset: At the interface between the cell and the quartz substrate, the plasma membrane is shown to warp around a vertical nanopillar. Intracellular structures and local curvatures on the plasma membrane resembling clathrin-mediated endocytosis events can be identified. (f, g) Zoomed-in FIB-SEM images of mitochondria (f) and nuclear envelope $(\mathrm{g})$. The insets clearly resolve the inner and outer membranes and interstitial space. Figures $\mathrm{e}-\mathrm{g}$ have been acquired from backscattered detectors (voltage: 5-10 kV, current: $0.64-1.4 \mathrm{nA}$ ), tilt is $52^{\circ}$, and original images are black-white inverted.

39 those having a smooth surface for osteoblast attachment, host40 implant integration, and the overall success of the implant. ${ }^{1,5}$ At 41 the cellular level, surfaces with nano- and micrometer 42 topographical features have been shown to actively affect cell 43 behavior such as stimulating stem cell differentiation, ${ }^{6}$ 44 enhancing osteoblast maturation, ${ }^{7}$ and regulating macrophage 45 activity. ${ }^{8}$ In this context, understanding how cells interact with 46 different features on the material surface is essential to study 47 how surface topologies regulate cell signaling, guide cell 48 migration, and control stem cell differentiation..$^{9-11}$

49 The most critical feature of the cell-to-material interface is 50 the cleft between the cell membrane and the material surface, 51 usually in the range of $50-200 \mathrm{~nm}$ for flat surfaces. ${ }^{12-14}$ 52 Sophisticated optical techniques have been developed to 53 measure the cleft distance, such as fluorescence interference 54 contrast (FLIC) microscopy, ${ }^{15-17}$ surface-generated structured 55 illumination microscopy, and variable incidence angle FLIC 56 microscopy (VIA-FLIC ${ }^{18}$ ). However, these interference-based 57 techniques are limited to smooth and reflective surfaces and are 58 not suitable for surfaces with topological features. Transmission 59 electron microscopy (TEM) is the most widely used method to directly visualize membrane structures at the nanoscale. ${ }^{13,14,19} 60$ However, TEM requires sectioning the sample into ultrathin 61 slices $(<100 \mathrm{~nm}$ thickness) with mechanical knives, a procedure 62 not compatible with a variety of substrate materials. For this 63 reason, the support material underneath the cells has to be 64 removed and the removal process by chemical or physical 65 treatment is often not feasible; even if feasible, the procedure is 66 challenging and can induce structural artifacts at the inter- 67 face. $^{13,20}$

\section{8}

A combination of focused ion beam (FIB) and scanning 69 electron microscopy (SEM) constitutes an alternative approach 70 for in situ imaging interfaces of any material and any desired 71 location. ${ }^{21}$ However, using FIB-SEM to examine the cell-to- 72 material interface is severely limited by the lack of contrast of 73 biological specimens and the sponge-like intracellular defects 74 induced by hard drying procedures. ${ }^{2-24}$ Resin-embedding 75 preparation with heavy metals allows the visualization of 76 intracellular structures even in the proximity of nanostruc- 77 tures, ${ }^{25,26}$ but the resin matrix around the cells does not allow 78 any visualization of the entire cell unless a 3D reconstruction of 79 the whole specimen is performed. Recently, thin-layer resin 80 

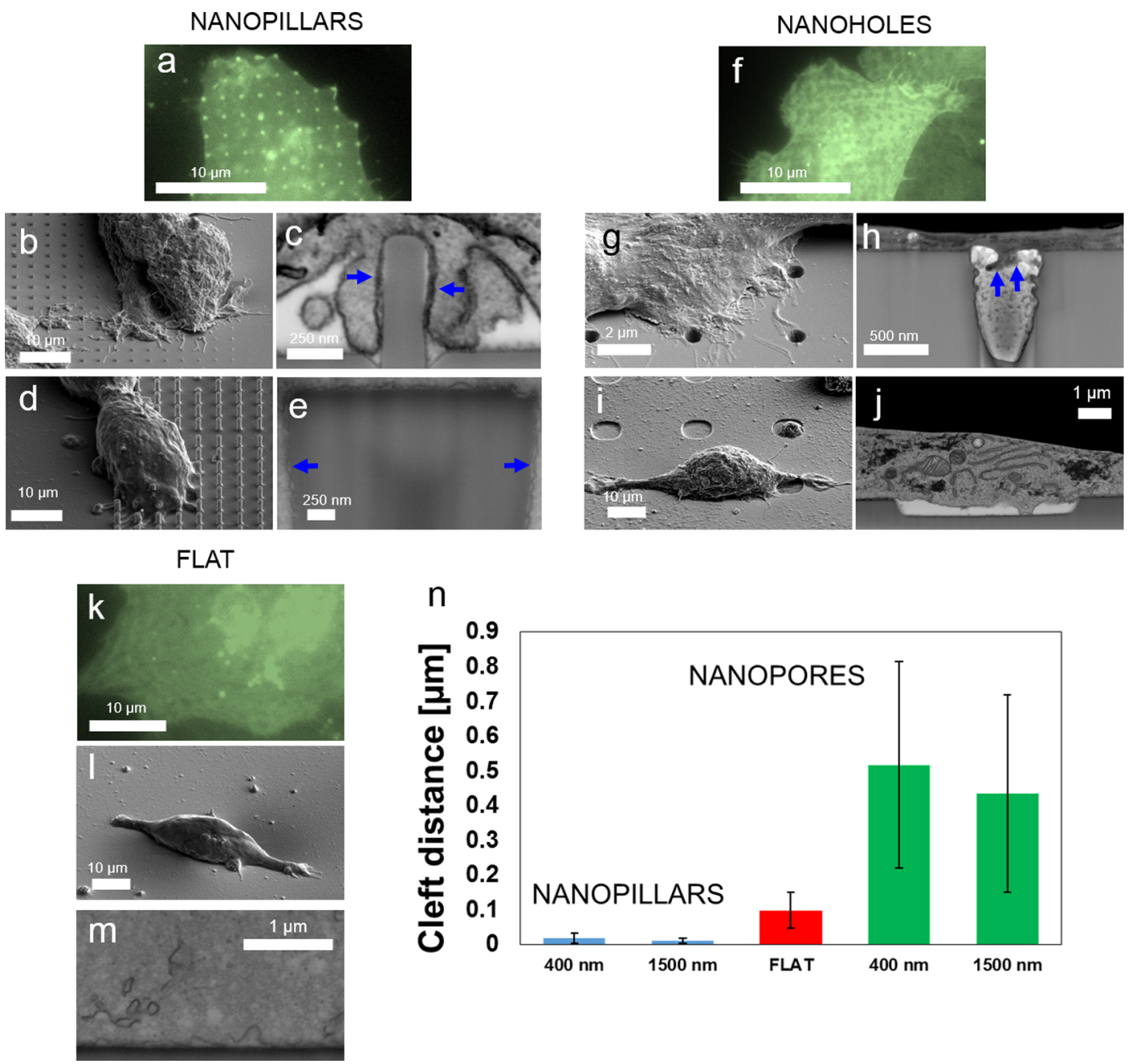

Figure 2. Surface topology drastically affects the cleft distance between the cell membrane and the material surface. (a, f, $k$ ) CAAX-GFP transfected cells in green on nanopillars (a), nanopores (f), and flat surface (k) showing accumulation (bright spots) of nanopillars and uniform distribution of nanopores and flat surface. (b, $d, g, i, l)$ SEM of plasticized HEK cells on nanopillar arrays (b, d), nanopore arrays (g, i), and a flat surface (l). (c, e, h, j) FIB cross sections revealing that the plasma membrane wraps tightly around nanopillars with 400 nm (c) and $1500 \mathrm{~nm}$ diameter (e), while it mostly grows on top of nanopores of about $400 \mathrm{~nm}$ in diameter (h) and tentatively grows inside the nanopore of about $6 \mu \mathrm{m}$ diameter but remains far away from the surface in most places $(j)$. ( $\mathrm{m}$ ) FIB cross section of a cell on a planar silicon surface showing the membrane-to-material contact at the interface. (n) Direct measurements showing that nanopillars reduce the cleft distance as compared to flat surfaces, while nanopores drastically increase the cleft distance.

81 embedding methods have been developed to allow the 82 visualization of cells on microstructures, ${ }^{24,27,28}$ but the contrast 83 of the resulting samples is still too low to clearly resolve the 84 membrane-to-material interface at the nanoscale. To date, there ${ }_{85}$ is no method that can reliably resolve the plasma membrane in 86 proximity to nano- and microstructures and thus to measure 87 the cleft distance between the cell membrane and the material 88 surface. Therefore, the question of how surface topology affects 89 the cleft distance remains largely unexplored.

90 In this work, we present a FIB-SEM method that can 91 precisely resolve the cell-to-substrate interface with $10 \mathrm{~nm}$ 92 resolution. At the core of our FIB-SEM method is a sample 93 preparation method based on controlled thin-resin plasticiza94 tion of adherent cells with heavy metal staining. Unlike the 95 usual hard drying methods, this procedure embeds cells in a 96 thin plastic layer, which not only preserves the subcellular ${ }_{97}$ structures but also provides a solid support for the subsequent 98 FIB milling.

\section{RESULTS AND DISCUSSION}

The thin-layer plasticization method includes five major steps: 100 cell fixation, heavy metal staining, resin infiltration, extracellular 101 resin removal, and resin polymerization (Figure 1a). Specifi- $102 \mathrm{fl}$ cally, mammalian cells cultured on the desired substrate are 103 fixed by glutaraldehyde to cross-link intracellular structures (i.e., 104 proteins) so that they can withstand the subsequent staining 105 and embedding processes without altering the interstitial space 106 between the membrane and the material surface. ${ }^{29,30}$ After 107 fixation, the cells are treated with osmium- and uranium-based 108 staining series (RO-T-O procedure ${ }^{31,32}$ and en bloc staining; see 109 Experimental Procedure for details), a critical step to provide 110 high contrast to membrane and protein structures. Then, cells 111 are infiltrated with liquid epoxy-based resin. Traditional resin- 112 embedding procedures for TEM typically result in a 2-5-mm- 113 thick polymer block, preventing the visualization of the whole- 114 cell morphology. In our method, after resin infiltration and 115 before resin polymerization, a resin-removal step is introduced 116 that strips off the excess extracellular resin by first draining and, 117 
118 then, flushing the sample with ethanol. This step thins down 119 the resin coating outside the cell membrane to tens of 120 nanometers while maintaining a stable intracellular resin 121 embedding. ${ }^{24}$ The final step involves curing the liquid resin 122 to a thin layer of plastic with cells embedded inside. Since 123 extracellular resin is largely removed, cell topography and 124 membrane protrusions in contact with the underlying substrate 125 are clearly visible under SEM. Figure $1 b$ shows a resin126 embedded HL-1 cell cultured on a quartz substrate with arrays 127 of nanopillars, and Supplementary S1 shows resin-embedded 128 PC12 cells and primary cortical neurons cultured on flat glass 129 substrates, where fine features of the cell membrane are well 130 preserved.

131 Samples prepared via thin-layer plasticization are directly 132 mounted on FIB-SEM for in situ examination of the cell-to133 substrate interface. For this purpose, we first examine a large 134 sample area by SEM to identify locations of interest, such as 135 places where cell membranes are in contact with topological 136 features such as nanopillars. Once a desired area is located, it is 137 coated with a thin layer of platinum to prevent sample damage 138 during the next FIB milling step (see Experimental Procedure 139 and Supplementary S2). Then, a high-energy gallium ion beam 140 (acceleration current of $0.74 \mathrm{nA}$ ) is focused on the sample to 141 cut through the platinum protection layer, the cell-embedded 142 thin plastic layer underneath, and at least $1 \mu \mathrm{m}$ deep into the 143 substrate. This process is repeated to remove material and 144 opens up a vertical surface (Figure $1 \mathrm{c}, \mathrm{d}$ ). Then, a low-current, 145 e.g., $80 \mathrm{pA}$, ion beam is used to remove redeposited material 146 and polish the cross section. This step is critical for limiting the 147 well-known curtaining phenomena and ion-induced structural 148 damage at the interface. ${ }^{33}$ SEM visualization of the cross 149 section clearly shows intracellular structures as well as the 150 interface between the cell membrane and the substrate (Figure 151 1e). Unlike previous FIB-SEM images that usually contain 152 sponge-like structures with no discernible subcellular struc153 tures, $^{24,27,34}$ our FIB-SEM images show very clear subcellular 154 structures such as the cell membrane, the nucleus, nucleoli, the 155 nuclear envelope, mitochondria, and intracellular membranes. 156 We note that the resin wash step of the thin-resin plasticization 157 procedure needs to be carried out gently to avoid over-removal 158 of the resin, which can cause cracks in the cell membrane and 159 intracellular space. For the heavy metal staining step, either 160 overstaining or understaining results in poor structural contrast 161 and lower resolution, similar to TEM samples. All FIB-SEM 162 images are black-and-white inverted. Original images are shown 163 in Supplementary S2.

164 To determine the resolution of our FIB-SEM method, we 165 have examined a group of well-characterized cellular compart166 ments using high-magnification SEM imaging. Figure 1f shows 167 a mitochondrion with clearly resolved inner and outer 168 membranes ( $\sim 10 \mathrm{~nm}$ distance) as well as the cristae structures. 169 Figure $1 \mathrm{~g}$ shows the structure of a nuclear envelope with well170 distinguishable inner and outer membranes, which are 171 separated by an interstitial space of about $20 \mathrm{~nm}$. Endoplasmic 172 reticulum (ER) structures as parallel running membranes can 173 be seen in the vicinity of the nucleus, and the associated small 174 granules attached to the membrane of the ER likely are 175 ribosomes (Supplementary S3). Other intracellular structures 176 such as multivesicular bodies and intracellular membrane can 177 also be resolved in Supplementary S3. Furthermore, a high178 magnification SEM image of the cell-substrate interface clearly 179 reveals that the plasma membrane is very close to the flat substrate surface and contours around local nanopillar features 180 (Figure 1e, inset).

The development of this FIB-SEM method allows us to 182 quantitatively address the question of how different surface 183 topographies affect the cell-substrate cleft distance. For this 184 study, we engineer $\mathrm{SiO}_{2}$ substrates (or $\mathrm{Si}$ substrates with a $\mathrm{SiO}_{2} 185$ surface layer) with different surface geometries, including 186 protrusions, invaginations, flat, and other complex structures 187 (see Experimental Procedure for fabrication details). The 188 protrusions are vertical nanopillars with diameters or lengths 189 varying from 200 to $1500 \mathrm{~nm}$, a height of $1 \mu \mathrm{m}$, and spacing of 190 3-5 $\mu \mathrm{m}$ (Figure 2b,d and Supplementary S4). The $191 \mathrm{f} 2$ invaginations are pores with diameters varying from 200 to 192 $6000 \mathrm{~nm}$, a depth of about $500 \mathrm{~nm}$ to $1 \mu \mathrm{m}$, and a spacing of 3193 $\mu \mathrm{m} \quad(20 \mu \mathrm{m}$ for the largest pore) (Figure 2g,i and 194 Supplementary S5). A cell on a flat surface is shown in Figure 195 21. The complex structures include nanotubes, nanobars, 196 irregular nanocones, nanoletters (CUIO), and grooves, and 197 they are shown in Supplementary S4 and S6. All substrates 198 were coated with poly-L-lysine or fibronectine to facilitate cell 199 adhesion. HEK or HL-1 cells were used for the studies. Cells 200 cultured on different substrates were processed for FIB-SEM 201 imaging using the aforementioned preparation method. SEM 202 images of cells cultured on flat, nanopillar, and nanopore 203 substrates before FIB milling show healthy and spread cell 204 morphology (Supplementary S7).

The FIB-SEM imaging reveals drastic differences in how cell 206 membranes respond to different substrate nanotopologies. For 207 substrates with protruding structures, the cell membrane 208 deforms readily and wraps conformably around the surface 209 topology, as shown in Figure 2c,e and Supplementary S8, for 210 nanopillars with $400 \mathrm{~nm}$ and about $1500 \mathrm{~nm}$ diameter, 211 respectively. For nanopillars of all diameters the cell membrane 212 is usually within $10-30 \mathrm{~nm}$ on average from the substrate 213 surface. In sharp contrast, for substrates with invaginating 214 structures, the cell membrane hardly deforms and does not 215 contour the surface of nanopores or the hollow centers of the 216 nanotubes (Supplementary S9). For small-diameter pores 217 (Figure $2 \mathrm{~h}$ ), the cell membrane extends into the pores slightly, 218 but the cleft distance is usually more than 10 times greater than 219 that for nanopillars. For nanopores as large as $6 \mu \mathrm{m}$ in diameter 220 and $500 \mathrm{~nm}$ in depth, the cell membrane is still far away from 221 the surface (Figure $2 \mathrm{j}$ ), but some attachment points are created 222 in the pore. For flat surfaces, the cell membrane remains close 223 to the surface (Figure $2 \mathrm{~m}$ ). A similar phenomenon is observed 224 in other complex structures (Supplementary S9). For 225 protruding structures such as nanobars, CUIO nanoletters, 226 and nanocones, the cell membrane is very close to the substrate 227 surface, while for invaginating structures such as grooves, the 228 cell membrane is far away from the substrate surface 229 (Supplementary S9). For nanotubes, the cell membrane 230 wraps tightly around the outside wall of the tube (protruding 231 structure), while it remains far away from the inner wall of the 232 hollow center (invaginating structure, Supplementary S9). This 233 is a surprising result, as previous studies suggest that the cell 234 membrane is highly deformable and can extend into pits as 235 small as $50 \mathrm{~nm}^{35,36}$

In order to evaluate the cleft formed between the plasma 237 membrane and different surface topographies, we systematically 238 measured the average cleft distance for surfaces with nanopillars 239 and nanopores with comparable dimensions and flat surfaces 240 (measurement statistics shown in Supplementary S10). As seen 241 in Figure 2n, the cleft distance is $\sim 100 \mathrm{~nm}(\operatorname{stdv} 50 \mathrm{~nm})$ for the 242 
243 flat surface, which agrees with previous studies. ${ }^{12,14}$ The cleft 244 distance decreases to $\sim 15 \mathrm{~nm}$ (stdv $10 \mathrm{~nm}$ ) for nanopillars, 245 while it increases to $>400 \mathrm{~nm}$ for nanopores (stdv $300 \mathrm{~nm}$ ). 246 These dramatic changes in the cleft width suggest that the 247 plasma membrane interacts with protruding and invaginating 248 surface topologies in fundamentally different ways. In addition, 249 we calculated the cleft area between the membrane and the 250 nanostructures for all the investigated nanoholes and nanopillar 251 types. The cleft index measurement confirms that the cleft area 252 increases in the presence of nanopores and decreases in the 253 presence of nanopillars (see Supplementary S10 and S11 for 254 details).

255 To corroborate the FIB-SEM studies, we also examined how 256 the plasma membrane interacts with different surface topologies 257 by fluorescence imaging. At the same time, we simultaneously 258 probed the distribution of actin filaments, which are well known 259 to participate in the dynamics and the formation of protrusions 260 or invaginations on the cell membrane. ${ }^{37,38}$ Cells were 261 cotransfected with two plasmids, CAAX-GFP, which serves as 262 a marker for the plasma membrane, and LifeAct-RFP, which is 263 widely used to visualize F-actin in cells. Fluorescence imaging of 264 CAAX-GFP confirms that the cell membrane wraps around 265 nanopillars (bright spots due to projection of the vertical 266 membrane in Figure 2a) but not nanopores or flat surfaces 267 (Figure 2f,k). LifeAct-RFP imaging shows that F-actin 268 accumulates strongly on nanopillar locations, but is absent at 269 nanopores (Supplementary S12) and flat surfaces (data not 270 shown). This preliminary result suggests that actin filaments 271 might be involved in forming the close contact between the cell 272 membrane and the nanopillars.

273 Next, we examine whether the topological effect for the 274 interface cleft depends on the chemical composition of the 275 material. Considering that our FIB-SEM method is applicable 276 to materials with diverse composition and stiffness, we 277 compared flat and nanopillar surfaces made of quartz (Young's 278 modulus $\sim 80 \mathrm{GPa})$ and conductive polymer blend poly $(3,4-$ 279 ethylenedioxythiophene):polystyrenesulfonate (PEDOT, 280 Young's modulus $\sim 1 \mathrm{GPa}$ ). Unlike quartz (shown as the gray 281 bottom layer in Figure $2 \mathrm{f}-\mathrm{i}$ ), PEDOT is conductive and 282 scatters electrons strongly (shown as the black bottom layer in 283 Figure 3b), which reduces the effective contrast of the 284 biological sample. Despite this, the FIB-SEM image in Figure 285 3b (cells before cut shown in Figure 3a) still clearly resolves the 286 cell membrane-surface gap, achieving the first cross section 287 visualization of cells on the PEDOT surface. Here, we 288 measured the effective distance of the plasma membrane 289 from the surface. The cell membrane is seen in close contact 290 with the flat PEDOT surface, and the average cleft distance is 291 measured to be $89 \pm 73 \mathrm{~nm}$ (stdv), similar to the cleft distance 292 for the flat quartz surface at $98 \pm 52 \mathrm{~nm}$ (stdv). Next, we 293 compared the cleft distances for nanopillar substrates made of 294 quartz and covered with a thin layer of PEDOT (Figure 3c,d). 295 Our measurements show that the average cleft distances for 296 quartz nanopillars and PEDOT nanopillars are similar $(15 \pm$ $2972.7 \mathrm{~nm}$ and $11 \pm 4.1 \mathrm{~nm}$, stdv) but much smaller than that for 298 the flat surfaces. The statistical details of these measurement are 299 shown in Supplementary S10.

300 Finally, we explored the capabilities of the FIB/SEM method 301 for volumetric imaging and multiangle imaging. FIB-SEM 302 allows repetitive milling and imaging, allowing the investigation 303 of a volume of interest (Figure $4 \mathrm{a}$ ). We used low current (e.g., $30480 \mathrm{pA}$ ) for sequential FIB milling, which achieves a slice 305 thickness of about $20-40 \mathrm{~nm}$ and well beyond the capability of
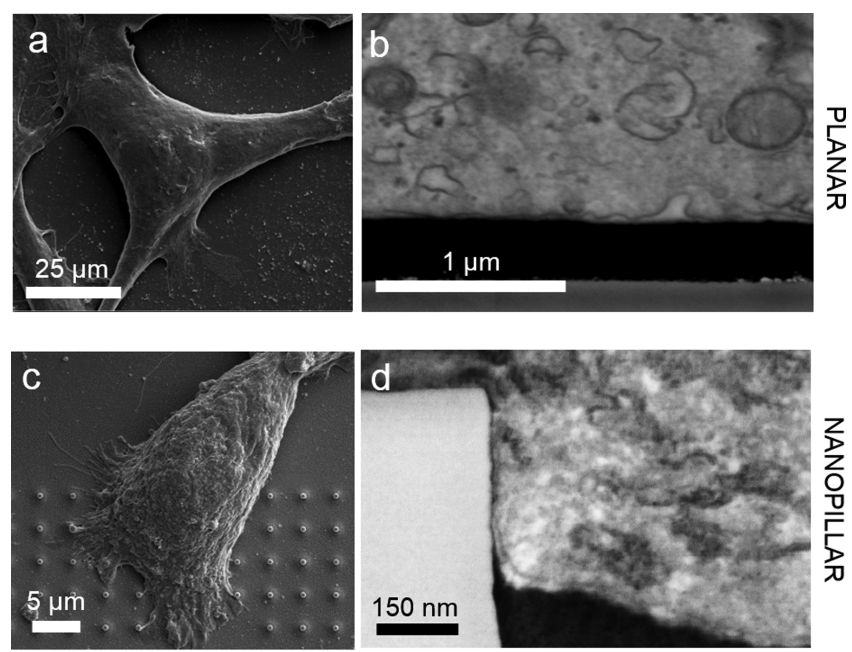

\begin{tabular}{ccccc}
\hline e & Q-Planar & P-Planar & Q-Nanopillar & P-Nanopillar \\
\hline $\begin{array}{c}\text { Average } \\
\text { Distance }\end{array}$ & $98 \mathrm{~nm}$ & $89 \mathrm{~nm}$ & $15 \mathrm{~nm}$ & $11 \mathrm{~nm}$ \\
Stdv & \pm 52 & \pm 73 & \pm 2.7 & \pm 4.1 \\
\hline
\end{tabular}

Figure 3. Comparison of quartz and PEDOT surfaces shows that the cleft distance is mainly determined by surface topologies. (a) SEM image of a plasticized HL-1 cell on planar PEDOT. (b) FIB cross section revealsing the plasma membrane and local ruffling on the planar PEDOT surface. (c) SEM image of a plasticized HL-1 cell on quartz nanopillars covered with a thin layer $(10-20 \mathrm{~nm})$ of PEDOT. (d) FIB cross section revealing the close contact of the plasma membrane to the PEDOT superficial layer on the nanopillar. (e) Quantitative analysis of the average cleft values and the corresponding standard deviation calculated for quartz $(Q)$ and PEDOT (P) substrates with planar and nanopillar surfaces showing that cleft values are comparable for the same structures but different materials.

mechanical slicing by means of ultramicrotomes $(70-200 \mathrm{~nm}) \cdot 306$ Figure $4 \mathrm{~b}, \mathrm{c}$ show two representative cross sections of the same 307 cell (shown in Figure 4a) interacting with two different lines of 308 nanopillars. By sequentially imaging a set of 72 sequential 309 sections, we reconstructed a $3 \mathrm{D}$ intracellular space and its 310 interaction with nanopillars using a segmented 3D reconstruc- 311 tion method (Figure 4d, Supplementary Movie 1). In particular, 312 we modeled the 3D morphology of the nuclear envelope, 313 nucleoli, and the nonadherent cellular membrane domain, 314 which were individually constructed and overlaid on the 315 remaining structures, as shown in Figure 4e. The nuclear 316 envelope appears to be bent upward on top of a nanopillar by 317 as much as $800 \mathrm{~nm}$ (Figure $4 \mathrm{f}$ ), agreeing well with our previous 318 observation by TEM.

Unlike the ultramicrotome sectioning method, which slices 320 materials sequentially in only one direction, the FIB-SEM 321 method is highly versatile and allows sectioning of the same 322 sample with different directions at multiple locations. This 323 capability is often important for cells with protrusions such as 324 neurons. Primary cortical neurons from embryonic rats were 325 cultured on a quartz substrate with arrays of solid nanopillars. 326 After 5 days of culturing in vitro, neurons were fixed and 327 processed for FIB-SEM imaging as described earlier. The SEM 328 image in Figure 4g (inset) shows a neuron cell body together 329 with multiple neurites growing out from the cell body. We first 330 identified four regions of interest from the SEM image: the cell 331 body, neurite-1, neurite-2, and neurite- 3 . Then, after coating a 332 layer of Pt, FIB milling was used to cut open the interfaces 333 


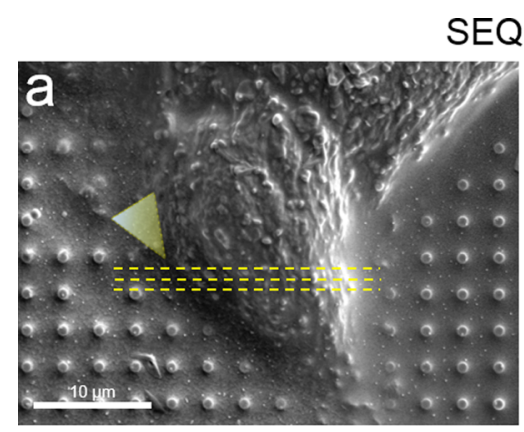

\section{ENTIAL MILLING}
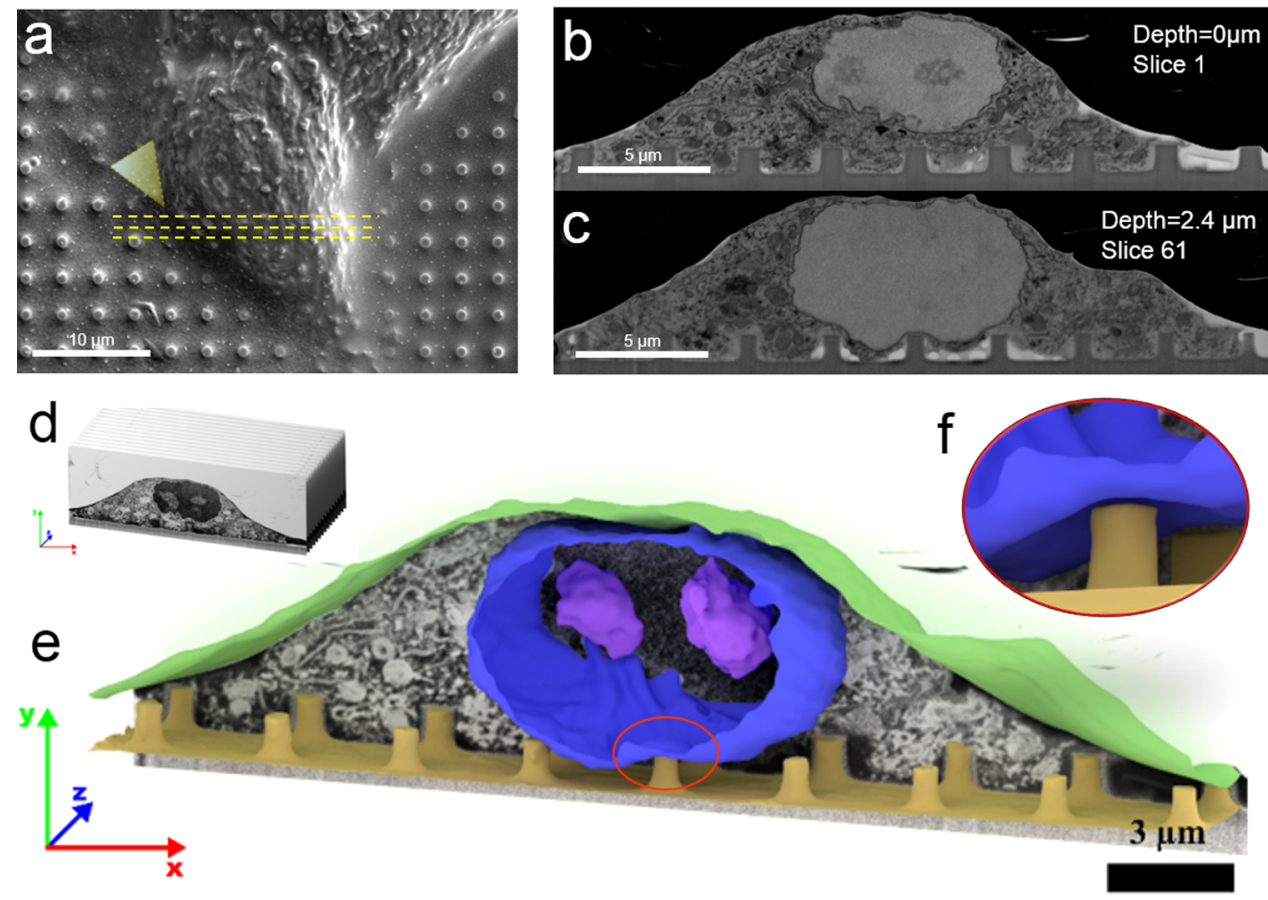

ANGLED MILLING
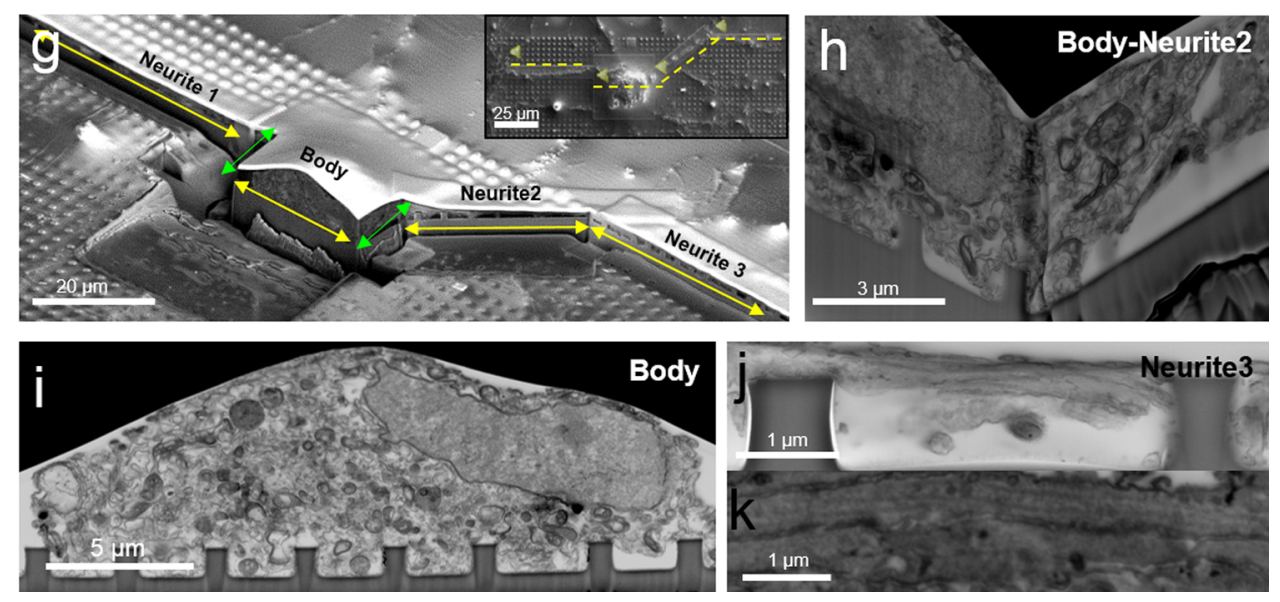

Figure 4. FIB-SEM for sequential volumetric imaging and multiangled imaging. (a) SEM image of a plasticized HL-1 on nanopillars where yellow dashed lines indicate the region of interest for the sequential milling. (b, c) SEM images of two exemplary slices from a stack of 78 slices at two different pillars' lines. (d-f) Images collected in the stack were assembled, segmented, and analyzed. Automated 3D reconstruction of the top membrane and the nuclear envelope overlaid on the SEM background image. Reconstruction shows that the nuclear envelope is deformed upward by a nanopillar. (g) FIB milling of a neuron where yellow arrows indicate the regions of interest and green lines indicate the connecting regions (the inset shows a SEM image of the same neuron before FIB milling). (h) FIB-SEM image of the bodyneurite 2 connecting region opened at a 90-degree angle. (i) FIB-SEM image of the neuronal body on a line of nanopillars. (j) FIB-SEM image of neurite 3 on top of nanopillars. (k) Zoomed-in image of neurites revealing multiple longitudinally oriented microtubules parallel to the direction of the neurite.

334 along six connecting lines (yellow arrowed lines corresponding 335 to four regions of interest and green arrowed lines being the 336 connecting lines in Figure 4g). FIB-SEM imaging of the cell 337 body shows the nucleus, a large number of intracellular 338 organelles, and the plasma membrane wrapping around the 339 nanopillars (Figure 4i). By multiangle milling, FIB-SEM also 340 offers the advantage of examining a location from multiple 341 directions, as shown by the 90-degree intersection between 342 neurite- 2 and the cell body (Figure $4 \mathrm{~h}$ ). The cross section of 343 neurite-3 is shown in Figure 4j, which illustrates a neurite 344 attached to the top and the side of two nanopillars. A magnified image of a neurite reveals multiple longitudinally orientated 345 microtubules parallel to the direction of the neurite (Figure 4k), 346 comparable in morphology to those investigated by TEM. ${ }^{40,41} 347$

\section{CONCLUSIONS}

We demonstrate a FIB-SEM method for imaging the cell-to- 349 material interface in situ, without removing the substrate. The 350 FIB-SEM method has the advantages of examining a large 351 sample area, opening up cross sections at any desired location, 352 achieving volume reconstruction, and performing multidirec- 353 tional milling. This method achieves a high contrast and 354 
355 resolution at $10 \mathrm{~nm}$ and is suitable to investigate the interface 356 between the cell membrane and nonbiological materials. Our 357 study reveals a surprising discovery that the cleft width between 358 the cell membrane and the substrate surface is strongly 359 influenced by the surface topology. As the cell attachment and 360 the membrane-to-material interface strongly influence the 361 performance of medical implants and biosensors, our study 362 suggests that surface topology is a crucial consideration for the 363 development of new materials and devices for biological 364 applications. Furthermore, as the FIB-SEM method is 365 compatible with a variety of substrate materials and top366 ographies, we expect that this method can be used for more 367 sophisticated in vivo studies such as examining the interfaces 368 between osteoblast and titanium implants. We also expect this 369 FIB-SEM method to be compatible with immunolabeling and 370 genetically encoded EM enhancers. ${ }^{42}$

\section{EXPERIMENTAL PROCEDURE}

\section{1. Nanostructure Fabrication, Characterization, and Prep-} 373 aration. Fabrication and Characterization of Quartz Nanopillars, 374 CUIO Structures, Nanobars, and Nanotubes. Nanostructures (NSs) 375 used in this work were fabricated on a 4 in. quartz wafer using 376 electron-beam lithography (EBL). In brief, the wafer was diced into 377 pieces $2 \mathrm{~cm} \times 2 \mathrm{~cm}$ square. After sonication cleaning in acetone and 2378 propanol, the pieces were spin-coated with $300 \mathrm{~nm}$ of ZEP-520 379 (ZEON Chemicals), followed by E-Spacer $300 \mathrm{Z}$ (Showa Denko). 380 Desired patterns were exposed by EBL (Raith150) and developed in 381 xylene. The mask was then created by sputter deposition of $100 \mathrm{~nm} \mathrm{Cr}$ 382 and lift-off in acetone. NSs was generated by reactive ion etching with $383 \mathrm{CHF}_{3}$ and $\mathrm{O}_{2}$ chemistry (AMT 8100 etcher, Applied Materials). 384 Before cell culture, the substrate was cleaned in $\mathrm{O}_{2}$ plasma and 385 immersed in Chromium Etchant 1020 (Transene) to remove $\mathrm{Cr}$ 386 masks. SEM (FEI Nova) imaging was performed on $3 \mathrm{~nm} \mathrm{Cr}$ 387 sputtered substrates to measure the dimensions of different NSs.

388 Silicon Nanocones. A monolayer polystyrene nanosphere (PS) 389 array, which consists of PSs with an average diameter of $3 \mu \mathrm{m}$, was self390 assembled on glass-based silicon substrates with the Langmuir391 Blodgett method. To control the effective intervals between the 392 formed silicon nanopillars, a reactive ion etching process with oxygen $393\left(\mathrm{O}_{2}\right)$ as an etching gas was then followed to shrink the PSs (with a 394 final diameter of $1 \mu \mathrm{m}$ ). Silicon nanocones were last formed on glass 395 substrates by introducing chlorine $\left(\mathrm{Cl}_{2}\right)$ and hydrogen bromide $(\mathrm{HBr})$ 396 gases to reactive-ion-etch the silicon materials exposed to the plasma. 397 Quartz Nanopillars with PEDOT:PSS Cover Layer. Fused silica 398 glass substrates were cleaned using a standard soap, acetone, 2399 propanol sonication sequence. Poly(3,4-ethylenedioxythiophene) 400 polystyrenesulfonate (PEDOT:PSS) (Heraeus, Clevios PH 1000) 401 solution in water was doped with $5 \mathrm{wt} \%$ ethylene glycol (EG), $0.1 \mathrm{wt}$ $402 \%$ dodecyl benzenesulfonic acid (DBSA) as a surfactant, and $1 \mathrm{wt} \%$ 403 (3-glycidyloxypropyl)trimethoxysilane (GOPTS) as a cross-linking 404 agent to improve film stability. EG, DBSA, and GOPS were all 405 obtained from Sigma-Aldrich. After spin-coating at $1000 \mathrm{rpm}$ for $2 \mathrm{~min}$ 406 the films were baked at $120{ }^{\circ} \mathrm{C}$ for $10 \mathrm{~min}$.

407 Furthermore, the nanopillar substrates were cleaned using an 408 oxygen plasma etch and the standard acetone 2-propanol sequence 409 without ultrasonication to protect the pillars. A similar PEDOT:PSS 410 solution was spin-coated at $3000 \mathrm{rpm}$ for $2 \mathrm{~min}$ and subsequently 411 baked for $10 \mathrm{~min}$ at $120{ }^{\circ} \mathrm{C}$ to create a uniform film covering the 412 pillars.

413 Nanopores. A $500 \mu \mathrm{m}$ thick (100) silicon wafer was used for the e414 beam writing. The sample was spin-coated with $300 \mathrm{~nm}$ of negative 415 electron-sensitive resist Ma-N 2403 (MicroChem Corp.) and then 416 baked at $100{ }^{\circ} \mathrm{C}$ for $4 \mathrm{~min}$. The pattern was written using an e-beam 417 lithography system (NanoBeam nB5) at $80 \mathrm{kV}$ and was developed in 418 Ma-D 525 developer (Microchem Corp.). A $50 \mathrm{~nm}$ layer of $\mathrm{Cr}$ metal 419 was deposited using e-beam evaporation for mask creation. After liftoff, 420 nanopores were created on the silicon wafer, defined by a $\mathrm{Cr}$ mask, and etched using an ICP-GSE200 etcher (North Microelectronics). 421 Finally, the $\mathrm{Cr}$ mask was removed by concentrated hydrochloric acid. 422 Silicon Grooves. The samples were manufactured at the Molecular 423 Foundry at Lawrence Berkeley National Laboratory under contract 424 DE-AC02-05CH11231.

FIB-Based Procedure. Quartz substrates were coated with a $200 \mathrm{~nm} 426$ thick layer of platinum. Nanopores $(1.5-3 \mu \mathrm{m}$ diameter, 3-5 $\mu \mathrm{m} 427$ pitch) were etched by focused ion beam (dual beam Helios 600i, at 30428 $\mathrm{kV}$ and a current of $40 \mathrm{pA}$ ). Afterward, the platinum layer was 429 removed by aqua regia overnight at room temperature.

Sample Preparation for Cell Culture. Quartz substrates were 431 treated with piranha solution with sulfuric acid and hydrogen peroxide 432 (Fisher Scientific), in a 7:1 dilution at room temperature overnight. 433 Samples were washed with distilled water, dried, and placed in $70 \% 434$ ethanol in a sterile hood. Samples were washed with sterile distilled 435 water and allowed to dry. After a 15 min UV light exposure, samples 436 were incubated overnight with $0.01 \%$ poly-L-lysine (Sigma Life 437 Science) for primary neurons and HEK cell cultures or with $1 \mathrm{mg} / 438$ $\mathrm{mL}$ fibronectin (Life Technologies) in $0.02 \%$ gelatin solution for HL-1 439 cells. COS-7 cells were directly plated on the substrate after 440 sterilization.

2. Cell Culture and Transfection. Primary Neurons. Cortices 442 were extracted from rat embryos at embryonic day 18 and incubated 443 with $0.25 \%$ trypsin/EDTA (Corning) in a $33 \mathrm{~mm}$ Petri dish for $5 \mathrm{~min} 444$ at $37^{\circ} \mathrm{C}$. The tissue-trypsin/EDTA solution was transferred into a 2445 $\mathrm{mL}$ plastic tube. The tissue settled at the bottom of the tube, and 446 leftover trypsin/EDTA was removed. Neurobasal media (Gibco) was 447 supplemented with 1\% B27 (Gibco), 0.25\% glutaMAX (Gibco), and 448 $0.1 \%$ gentamycin antibiotic (Gibco). One milliliter of warm media was 449 added, and then the tube was gently swirled by hand. This procedure 450 was repeated five times, and after the last media exchange, the tissue 451 was dissociated until resulting in a cell solution. A total of 80000 cells 452 were suspended in $3 \mathrm{~mL}$ and placed on each substrate. The media was 453 replaced completely $2 \mathrm{~h}$ after seeding time. Every second day, half of 454 the media was exchanged with freshly prepared warm (supplemented) 455 Neurobasal media.

HL-1 Cells. Confluent HL-1 cells, cultured in a $33 \mathrm{~mm}$ Petri dish, 457 were incubated with $1 \mathrm{~mL}$ of $0.25 \%$ trypsin/EDTA for $5 \mathrm{~min}$ at $37^{\circ} \mathrm{C} .458$ The cell-trypsin solution was transferred into a $15 \mathrm{~mL}$ tube, and $2 \mathrm{~mL} 459$ of Claycomb media (Sigma Life Science) supplemented with $10 \%$ fetal 460 bovine serum (Sigma-Aldrich), $100 \mu \mathrm{g} / \mathrm{mL}$ penicillin/streptomycin 461 (Sigma Life Science), $0.1 \mathrm{mM}$ norepinephrine (Sigma-Aldrich), and 2462 mM glutaMAX were added. The cell solution was placed in a 463 centrifuge for $3 \mathrm{~min}$ with a rotation of $1300 \mathrm{rpm}$. The cell pellet was 464 resuspended in $1 \mathrm{~mL}$ of media, and $50 \mu \mathrm{L}$ of the resuspension was 465 plated on each substrate in addition to $3 \mathrm{~mL}$ of supplemented media. 466

HEK 293 Cells. HEK 293 expressing channels NaV 1.3 and KIR 2.1467 were acquired by Adam Cohen laboratory and maintained in DMEM/ 468 F12 (Gibco), 10\% FBS (Gibco), 1\% penicillin/streptomycin (100 $\mu \mathrm{g} / 469$ $\mathrm{mL}, \mathrm{Gibco})$, Geneticin $(500 \mu \mathrm{g} / \mathrm{mL}, \mathrm{Gibco})$, and puromycin $(2 \mu \mathrm{g} / 470$ $\mathrm{mL}$, Fisher Scientific). At $80 \%$ confluency, cells were divided, 471 resuspended, and plated on quartz substrates as for HL-1 cells. 472

COS-7 and U2OS Cells. Cells were maintained in DMEM 473 supplemented with $10 \%$ fetal bovine serum, and at $90 \%$ confluency 474 they were divided as for HL- 1 cells and plated on the substrates. 475

CAAX/LifeAct Transfection. U2OS cells were cultured in DMEM 476 medium (HyClone) with $10 \%$ fetal bovine serum (Gibco) and $1 \% 477$ penicillin/streptomycin (Invitrogen) at $37{ }^{\circ} \mathrm{C}$ in $5 \% \mathrm{CO}_{2}$. Trans- 478 fection was preformed using electroporation (Amaxa Nucleofector) 479 with the manufacturer's protocol. U2OS cells were transfected with 480 Lifeact-RFP (transformed bacteria acquired from AddGene) and Caax- 481 GFP and plated on a nanostructured surface for at least $16 \mathrm{~h}$ before 482 examination.

3. Ultrathin Plastification and RO-T-O Procedure. Substrates 484 with cells were rinsed with $0.1 \mathrm{M}$ sodium cacodylate buffer (Electron 485 Microscopy Sciences) and fixed with $3.2 \%$ glutaraldehyde (Sigma- 486 Aldrich) at $4{ }^{\circ} \mathrm{C}$ overnight. Specimens were then washed $(3 \times 5 \mathrm{~min}) 487$ with chilled buffer and quenched with chilled $20 \mathrm{mM}$ glycine solution 488 $(20 \mathrm{~min})$. After rinsing $(3 \times 5 \mathrm{~min})$ with chilled buffer specimens were 489 postfixed with equal volumes of $4 \%$ osmium tetroxide and $2 \% 490$ 
491 potassium ferrocyanide (Electron Microscopy Sciences, RO step) (1 h 492 on ice). Samples were then washed with chilled buffer $(3 \times 5 \mathrm{~min})$, 493 and the solution was replaced with freshly prepared $1 \%$ thiocarbohy494 drazide (Electron Microscopy Sciences, $\mathrm{T}$ step) (20 min at room 495 temperature). After rinsing with buffer $(2 \times 5 \mathrm{~min})$, the samples were 496 incubated with $2 \%$ aqueous osmium tetroxide (O step) (30 min at 497 room temperature). Cells were again rinsed $(2 \times 5 \mathrm{~min})$ with distilled 498 water and then, finally, incubated with syringe-filtered $4 \%$ aqueous 499 uranyl acetate (Electron Microscopy Sciences, en bloc step) (overnight $\left.5004{ }^{\circ} \mathrm{C}\right)$. Cells were rinsed $(3 \times 5 \mathrm{~min})$ with chilled distilled water, 501 followed by gradual dehydration in an increasing ethanol series $(10 \%-$ $50230 \%-50 \%-70 \%-90 \%-100 \%, 5-10 \mathrm{~min}$ each on ice). The last 503 exchange with a $100 \%$ ethanol solution was performed at room 504 temperature. Epoxy-based resin solution was prepared as previously 505 described, ${ }^{24}$ and samples were infiltrated with increasing concen506 trations of resin in 100\% ethanol, using these ratios: 1:3 (3 h), 1:2 (3 $507 \mathrm{~h}), 1: 1$ (overnight), 2:1 (3 h), 3:1 (3 h). Infiltration was carried out at 508 room temperature and in a sealed container to prevent evaporation of 509 ethanol. Samples were then infiltrated with $100 \%$ resin overnight at 510 room temperature. The excess resin removal was carried out by first 511 draining away most of the resin by mounting the sample vertically for $5121 \mathrm{~h}$ and, then, rapidly rinsing with $100 \%$ ethanol prior to 513 polymerization at $60{ }^{\circ} \mathrm{C}$ overnight.

\section{4. Scanning Electron Microscopy Imaging and Focused Ion} 515 Beam Sectioning. Sample Preparation. Each sample was glued with 516 colloidal silver paste (Ted Pella Inc.) to a standard stub $18 \mathrm{~mm}$ pin 517 mount (Ted Pella Inc.). A very thin layer of gold-palladium alloy was 518 sputtered on the sample before imaging.

519 SEM Imaging. Samples were loaded into the vacuum chamber of a 520 dual-beam Helios Nanolab600i FIB-SEM (FEI). For selecting a region 521 of interest, an (electron) beam with an accelerating voltage of $3-5 \mathrm{kV}$ 522 and current of $21 \mathrm{pA}$ to $1.4 \mathrm{nA}$ was applied. For image acquisition of 523 whole cells (i.e., Figure 1b) a secondary electron detector was used. 524 For cross section imaging, a beam acceleration voltage of $2-10 \mathrm{kV}$ was 525 selected, with the current ranging between 0.17 and $1.4 \mathrm{nA}$, while 526 using a backscattered electron detector (immersion mode, dynamic 527 focus disabled in cross section, stage bias zero), a dwell time of $100 \mu \mathrm{s}$, 528 and $3072 \times 2048$ pixel store resolution. For the sequential sectioning, 529 the function iSPI was enabled in order to slice and acquire an image of 530 the stack every $38.5 \mathrm{~nm}$ with $5 \mathrm{kV}$ voltage, $1.4 \mathrm{nA}$ current, and $1024 \times$ 531884 resolution.

532 FIB Sectioning. Regions of interest were preserved by electron533 assisted deposition of a $0.5 \mu \mathrm{m}$ double platinum layer and ion-assisted 534 deposition of a (nominal) $1 \mu \mathrm{m}$ thick coating. First, trenches were 535 created with an etching procedure fixing an acceleration voltage of 30 $536 \mathrm{kV}$ and currents in the range 9.1-0.74 $\mathrm{nA}$ depending on the effective 537 area to remove. A fine polishing procedure of the resulting cross 538 sections was carried out on the sections, with a voltage of $30 \mathrm{kV}$ and 539 lower currents in the range $0.74 \mathrm{nA}$ to $80 \mathrm{pA}$ so that redeposition 540 phenomena in the cross section are very limited.

541 Image Analysis and 3D Reconstruction. All images were 542 preprocessed with ImageJ (National Institutes of Health, USA, 543 http://imagej.nih.gov/ij). The images of the sequential cross sections 544 shown in Figure 2 were collected as a stack, analyzed, and processed 545 with an open source tool chain based on Python (Python Software 546 Foundation, USA, http://www.python.org) scripts and tools. The 547 image stack was cropped, filtered, and down-sampled. The isotropic 548 resolution in $x, y$, and $z$ amounts to $38.5 \mathrm{~nm}$. The reconstructed data 549 are visualized with Blender (Blender Foundation, The Netherlands, 550 http://www.blender.org).

551 Cleft Distance. The average cleft distance has been calculated by 552 selecting 10 equally distributed points on the part of the plasma 553 membrane that surrounds the nanostructures. For each point, the 554 distance is measured as the shortest distance between the membrane 555 and the material surface. The number of points, the number of 556 nanostructures, and the number of cells that are used to calculate the 557 average number (and the standard deviations of the mean) are listed in 558 Supplementary Table S10. The measurements have been performed 559 with ImageJ.

\section{ASSOCIATED CONTENT}

S Supporting Information

The Supporting Information is available free of charge on the 562 ACS Publications website at DOI: 10.1021/acsnano.7b03494. 563

\section{Movie (AVI)} 564 Ultrathin plasticization of cells on planar substrates, 565 sectioning procedure, ultrastructure resolution, substrate 566 geometry of nanopillars and nanocones, substrate 567 geometry of nanopores, substrate geometry of CUI, 568 nanobars, nanotubes, and grooves, SEM of cells on a flat 569 surface and diverse nanostructures, cleft between cells 570 and flat, nanopillar, and nanopore surfaces, cleft visual- 571 ization for cells on complex structures, cleft distance, cleft 572 index, CAAX/ACTIN cotransfection (PDF)

AUTHOR INFORMATION

\section{Corresponding Authors}

*E-mail: santorof@stanford.edu.

*E-mail: bcui@stanford.edu.

Yoeri van de Burgt: 0000-0003-3472-0148

Bianxiao Cui: 0000-0002-8044-5629

$\square$ Department of Mechanical Engineering and Institute for ${ }_{582}$ Complex Molecular Systems, Eindhoven University of 583 Technology, 5612 AZ, Eindhoven, The Netherlands. 584 IItalian Institute of Technology-Center of Advanced Bio- 585 materials and Healthcare, 80125, Naples, Italy.

Notes

The authors declare no competing financial interest.

The authors thank the Stanford Nano Shared Facility (SNSF) 590 for a seed grant to a complementary use of the Helios 600i and 591 Dr. Juliet Jamtgaard and Dr. Richard Chin for the useful 592 discussions. The authors also acknowledge the Heart Rhythm 593 Society for F.S.'s research fellowship, the National Science 594 Foundation for the grants NSF 1055112 and NSF 1344302. 595 Y.V.B was a user project at the Molecular Foundry, Lawrence 596 Berkeley National Laboratory, all supported by the Office of 597 Science, Office of Basic Energy Sciences, U.S. Department of 598 Energy, under contract DE-AC02-05CH11231.

599

\section{REFERENCES}

600

(1) Langer, R.; Tirrell, D. A. Designing Materials for Biology and 601 Medicine. Nature 2004, 428, 487-492. 602

(2) Anderson, J. M. Biological Responses to Materials. Annu. Rev. 603 Mater. Res. 2001, 31, 81-110.

(3) Kieswetter, K.; Schwartz, Z.; Dean, D. D.; Boyan, B. D. The Role 605 of Implant Surface Characteristics in the Healing of Bone. Crit. Rev. 606 Oral Biol. Med. 1996, 7, 329-345.

(4) Rychly, J.; Nebe, B. Interface Biology of Implants. Cell Adhes. 608 Migr. 2009, 3, 390-394.

(5) Olivares-Navarrete, R.; Hyzy, S. L.; Berg, M. E.; Schneider, J. M.; 610 Hotchkiss, K.; Schwartz, Z.; Boyan, B. D. Osteoblast Lineage Cells 611 Can Discriminate Microscale Topographic Features on Titanium- 612 Aluminum-Vanadium Surfaces. Ann. Biomed. Eng. 2014, 42, 2551- 613 2561.

(6) Chen, W.; Shao, Y.; Li, X.; Zhao, G.; Fu, J. Nanotopographical 615 Surfaces for Stem Cell Fate Control: Engineering Mechanobiology 616 from the Bottom. Nano Today 2014, 9, 759-784. 
618 (7) Schneider, G. B.; Perinpanayagam, H.; Clegg, M.; Zaharias, R.; 619 Seabold, D.; Keller, J.; Stanford, C. Implant Surface Roughness Affects 620 Osteoblast Gene Expression. J. Dent. Res. 2003, 82, 372-376.

621 (8) Luu, T. U.; Gott, S. C.; Woo, B. W. K.; Rao, M. P.; Liu, W. F. 622 Micro- and Nanopatterned Topographical Cues for Regulating 623 Macrophage Cell Shape and Phenotype. ACS Appl. Mater. Interfaces 624 2015, 7, 28665-28672.

625 (9) Stevens, M. M.; George, J. H. Exploring and Engineering the Cell 626 Surface Interface. Science 2005, 310, 1135-1138.

627 (10) Kasemo, B. Biological Surface Science. Surf. Sci. 2002, 500, 628 656-677.

629 (11) Oh, S.; Brammer, K. S.; Li, Y. S. J.; Teng, D.; Engler, A. J.; 630 Chien, S.; Jin, S. Stem Cell Fate Dictated Solely by Altered Nanotube 631 Dimension. Proc. Natl. Acad. Sci. U. S. A. 2009, 106, 2130-2135.

632 (12) Toma, K.; Kano, H.; Offenhäusser, A. Label-Free Measurement 633 of Cell-Electrode Cleft Gap Distance with High Spatial Resolution 634 Surface Plasmon Microscopy. ACS Nano 2014, 8, 12612-12619.

635 (13) Hanson, L.; Lin, Z. C.; Xie, C.; Cui, Y.; Cui, B. Characterization 636 of the Cell-Nanopillar Interface by Transmission Electron Microscopy. 637 Nano Lett. 2012, 12, 5815-5820.

638 (14) Wrobel, G.; Höller, M.; Ingebrandt, S.; Dieluweit, S.; 639 Sommerhage, F.; Bochem, H. P.; Offenhäusser, A. Transmission 640 Electron Microscopy Study of the Cell-sensor Interface. J. R. Soc., 641 Interface 2008, 5, 213-222.

642 (15) Kiessling, V.; Tamm, L. K. Measuring Distances in Supported 643 Bilayers by Fluorescence Interference-Contrast Microscopy: Polymer 644 Supports and SNARE Proteins. Biophys. J. 2003, 84, 408-418.

645 (16) Lambacher, A.; Fromherz, P. Fluorescence Interference646 Contrast Microscopy on Oxidized Silicon Using a Monomolecular 647 Dye Layer. Appl. Phys. A: Mater. Sci. Process. 1996, 63, 207-216.

648 (17) Braun, D.; Fromherz, P. Fluorescence Interference-Contrast 649 Microscopy of Cell Adhesion on Oxidized Silicon. Appl. Phys. A: 650 Mater. Sci. Process. 1997, 65, 341-348.

651 (18) Ajo-Franklin, C. M.; Ganesan, P. V.; Boxer, S. G. Variable 652 Incidence Angle Fluorescence Interference Contrast Microscopy for Z653 Imaging Single Objects. Biophys. J. 2005, 89, 2759-2769.

654 (19) Fendyur, A.; Mazurski, N.; Shappir, J.; Spira, M. E. Formation of 655 Essential Ultrastructural Interface between Cultured Hippocampal 656 Cells and Gold Mushroom-Shaped MEA- Toward "IN-CELL" 657 Recordings from Vertebrate Neurons. Front. Neuroeng. 2011, 658 4.10.3389/fneng.2011.00014

659 (20) Hai, A.; Kamber, D.; Malkinson, G.; Erez, H.; Mazurski, N.; 660 Shappir, J.; Spira, M. E. Changing Gears from Chemical Adhesion of 661 Cells to Flat Substrata toward Engulfment of Micro-Protrusions by 662 Active Mechanisms. J. Neural Eng. 2009, 6, 066009.

663 (21) Narayan, K.; Subramaniam, S. Focused Ion Beams in Biology. 664 Nat. Methods 2015, 12, 1021-1031.

665 (22) Boyde, A.; MacOnnachie, E. Volume Changes during 666 Preparation of Mouse Embryonic Tissue for Scanning Electron 667 Microscopy. Scanning 1979, 2, 149-163.

668 (23) Gusnard, D.; Kirschner, R. H. Cell and Organelle Shrinkage 669 during Preparation for Scanning Electron Microscopy: Effects of 670 Fixation, Dehydration and Critical Point Drying. J. Microsc. 1977, 110, $67151-57$.

672 (24) Belu, A.; Schnitker, J.; Bertazzo, S.; Neumann, E.; Mayer, D.; 673 Offenhäusser, A.; Santoro, F. Ultra-Thin Resin Embedding Method for 674 Scanning Electron Microscopy of Individual Cells on High and Low 675 Aspect Ratio 3D Nanostructures. J. Microsc. 2016, 263, 78-86.

676 (25) Persson, H.; Købler, C.; Mølhave, K.; Samuelson, L.; 677 Tegenfeldt, J. O.; Oredsson, S.; Prinz, C. N. Fibroblasts Cultured on 678 Nanowires Exhibit Low Motility, Impaired Cell Division, and DNA 679 Damage. Small 2013, 9, 4006-4016.

680 (26) Wierzbicki, R.; Købler, C.; Jensen, M. R. B.; Łopacińska, J.; 681 Schmidt, M. S.; Skolimowski, M.; Abeille, F.; Qvortrup, K.; Mølhave, $682 \mathrm{~K}$. Mapping the Complex Morphology of Cell Interactions with 683 Nanowire Substrates Using FIB-SEM. PLoS One 2013, 8, e53307.

684 (27) Bittermann, A. G.; Burkhardt, C.; Hall, H. Imaging of Cell-to685 Material Interfaces by SEM after in Situ Focused Ion Beam Milling on
Flat Surfaces and Complex 3D-Fibrous Structures. Adv. Eng. Mater. 686 2009, 11, B182-B188.

(28) Seyock, S.; Maybeck, V.; Offenhäusser, A. How to Image Cell 688 Adhesion on Soft Polymers? Micron 2017, 92, 39-42. 689

(29) Collins, V. P.; Arborgh, B.; Brunk, U. A Comparison of the 690 Effects of Three Widely Used Glutaraldehyde Fixatives on Cellular 691 Volume and Structure. Acta Pathol. Microbiol. Scand., Sect. A 1977, 692 $85 A, 157-168$.

693

(30) Jeansson, M.; Haraldsson, B. Morphological and Functional 694 Evidence for an Important Role of the Endothelial Cell Glycocalyx in 695 the Glomerular Barrier. Am. J. Physiol. - Ren. Physiol. 2006, 290, F111- 696 F116.

(31) Tapia, J. C.; Kasthuri, N.; Hayworth, K. J.; Schalek, R.; 698 Lichtman, J. W.; Smith, S. J.; Buchanan, J. High-Contrast En Bloc 699 Staining of Neuronal Tissue for Field Emission Scanning Electron 700 Microscopy. Nat. Protoc. 2012, 7, 193-206.

(32) Bushby, A. J.; P’ng, K. M. Y.; Young, R. D.; Pinali, C.; Knupp, 702 C.; Quantock, A. J. Imaging Three-Dimensional Tissue Architectures 703 by Focused Ion Beam Scanning Electron Microscopy. Nat. Protoc. 704 2011, 6, 845-858.

(33) Santoro, F.; Neumann, E.; Panaitov, G.; Offenhäusser, A. FIB 706 Section of Cell-electrode Interface: An Approach for Reducing 707 Curtaining Effects. Microelectron. Eng. 2014, 124, 17-21. 708

(34) Santoro, F.; Dasgupta, S.; Schnitker, J.; Auth, T.; Neumann, E.; 709 Panaitov, G.; Gompper, G.; Offenhäusser, A. Interfacing Electrogenic 710 Cells with 3D Nanoelectrodes: Position, Shape, and Size Matter. ACS 711 Nano 2014, 8, 6713-6723.

(35) Moran-Mirabal, J. M.; Torres, A. J.; Samiee, K. T.; Baird, B. A.; 713 Craighead, H. G. Cell Investigation of Nanostructures: Zero-Mode 714 Waveguides for Plasma Membrane Studies with Single Molecule 715 Resolution. Nanotechnology 2007, 18, 195101.

(36) Richards, C. I.; Luong, K.; Srinivasan, R.; Turner, S. W.; 717 Dougherty, D. A.; Korlach, J.; Lester, H. A. Live-Cell Imaging of Single 718 Receptor Composition Using Zero-Mode Waveguide Nanostructures. 719 Nano Lett. 2012, 12, 3690-3694.

(37) Atilgan, E.; Wirtz, D.; Sun, S. X. Mechanics and Dynamics of 721 Actin-Driven Thin Membrane Protrusions. Biophys. J. 2006, 90, 65- 722 76.

(38) Schafer, D. A. Coupling Actin Dynamics and Membrane 724 Dynamics during Endocytosis. Curr. Opin. Cell Biol. 2002, 14, 76-81. 725

(39) Hanson, L.; Zhao, W.; Lou, H.-Y.; Lin, Z. C.; Lee, S. W.; 726 Chowdary, P.; Cui, Y.; Cui, B. Vertical Nanopillars for in Situ Probing 727 of Nuclear Mechanics in Adherent Cells. Nat. Nanotechnol. 2015, 10, 728 $554-562$.

729

(40) Bartlett, W. P.; Banker, G. A. An Electron Microscopic Study of 730 the Development of Axons and Dendrites by Hippocampal Neurons in 731 Culture. I. Cells Which Develop without Intercellular Contacts. J. 732 Neurosci. 1984, 4, 1944-1953.

(41) Maxwell, W. L. Damage to Myelin and Oligodendrocytes: A 734 Role in Chronic Outcomes Following Traumatic Brain Injury? Brain 735 Sci. 2013, 3, 1374-1394.

(42) Lam, S. S.; Martell, J. D.; Kamer, K. J.; Deerinck, T. J.; Ellisman, 737 M. H.; Mootha, V. K.; Ting, A. Y. Directed Evolution of APEX2 for 738 Electron Microscopy and Proximity Labeling. Nat. Methods 2015, 12, 739 $51-54$. 